\title{
Mas o filme é sobre o quê? Estudo sobre os grandes lançamentos cinematográficos
}

\author{
Augusto OliveirA*
}

\begin{abstract}
Resumo: Este artigo toma a indústria do entretenimento como lugar privilegiado para entendermos características fundamentais da chamada "sociedade do espetáculo". Para tal, analisamos a lógica de alguns grandes lançamentos cinematográficos, como $O$ código da Vinci, A paixão de Cristo e Matrix.
\end{abstract}

Palavras-chave: cinema; sociedade do espetáculo; capitalismo.

\section{Introdução}

Este escrito é um ensaio sobre fenômenos midiáticos de nosso tempo. A maior parte do que foi escrito aqui tem como inspiração maior os famosos aforismos sobre a "sociedade do espetáculo". "O espetáculo não é um conjunto de imagens mas uma relação social entre pessoas, mediada por imagens" (Debord, 1997, p. 14). Os fenômenos midiáticos que irei comentar são os lançamentos cinematográficos de grandes estúdios de cinema estadunidenses.

\section{O caso mais recente}

Para falar a verdade, não sei de onde veio a onda em torno do livro $O$ código da Vinci, que recentemente ganhou uma versão cinematográfica - como se sabe, o livro se tornou uma superprodução da Columbia Pictures, ${ }^{1}$ um dos grandes estúdios de cinema estadunidense. Para continuar falando a verdade, além de assistir ao filme, fiz apenas uma leitura superficial do livro, folheando a maioria das páginas. Por isso, não me arrisco a elaborar profundamente o teor de seu conteúdo. Seria um realismo fantástico como

*Doutor em Sociologia e pesquisador da UFF.

1. O filme foi lançado em 2006. Foi dirigido por Ron Howard e protagonizado por Tom Hanks. o de um Carlos Castañeda em A erva do diabo destinado a fazer o homem comum refletir sobre o cotidiano a partir de uma narrativa fantástica, mas verossímil? Trabalho arqueológico acadêmico com vistas a expor evidências sobre fatos históricos? Tratar-se-ia de uma Agatha Christie consultando uma enciclopédia da história universal ? ${ }^{2}$ Parece não haver maiores dificuldades em dizer que se trata da última opção: em nenhum momento da leitura, há indicações claras de que o livro não é uma obra de ficção. No entanto, desconheço que os livros de Agatha Christie tenham feito entidades representantes dos mordomos (lembremos que o assassino sempre é o mordomo) se exaltarem a ponto de recomendar que as pessoas não lessem tais livros como fizeram setores da Igreja Católica em relação ao livro/filme Código da Vinci.

Por que a circulação de uma obra de ficção despertou tamanha indignação dos atores sociais reais incomodados com seus similares ficcionais (como a organização católica Opus Dei)? A resposta é simples: isso ocorreu porque leitores em geral tomaram aquela narrativa como "descoberta arqueológica", a ponto de os personagens realmente existentes citados na trama se

2. Consultando-se o site de Dan Brown, tem-se uma biografia muito exígua, talvez para dar o clima de mistério. Somente é dito que ele foi professor de inglês. 
sentirem na obrigação de criticá-la, negá-la, confirmá-la, enfim, posicionar-se. A pergunta seria então: por que leitores (em geral) fizeram tal leitura? Essa pergunta parece-me a mais adequada (e também mais complexa de ser respondida). Vamos a ela.

Sem negar a evidência de que um mesmo texto pode receber inúmeras leituras, creio que essa leitura "empiricista" não se deva ao acaso e nem mesmo a um possível "despreparo historiográfico" de grande parte do público. Saltoume aos olhos o fato de que o livro $O$ código da Vinci foi sucedido de um sem-número de edições (nem todas da mesma editora que lançara o referido livro) de "explicações" sobre o livro. ${ }^{3}$ Imaginemos o seguinte cenário: Dante Alighieri lança sua Divina comédia e vários outros escritores de seu tempo se lançam numa frenética explicação sobre o conteúdo de sua obra. Essa explicação não seria nada parecida com a análise estilística ou a hermenêutica interna praticada pelo cânone acadêmico: tratar-se-ia de dizer (ou pelo menos de lançar polêmica sobre) quantos quilômetros haveria de ter o purgatório, a temperatura do inferno e a velocidade da brisa que corre no paraíso. Sem querermos estipular quem vem primeiro - a leitura de apoio ao livro ou o assombro do leitor -, o fato é que o tratamento realista desses interlocutores ${ }^{4}$ atiça o leitor comum a tomar a narrativa ficcional como uma espécie de versão romanceada da "verdadeira verdade". Excitado com o que outros leitores falam e com a leitura de apoio a dar informações, o leitor imagina: esta verdadeira verdade, de tão exuberante, só poderia ser formulada em termos de romance. E continua: só há uma razão para que a verdade apareça assim desta forma; a razão é que os vilóes da narrativa são vilões da vida real e o escritor romanceia para se proteger.

Mas a dura realidade é outra: o que é $O$ código da Vinci senão uma major mercadoria multinacional ${ }^{5}$ na estante da livraria/sala de cinema perto da minha casa? E o que são os

\footnotetext{
3. Elas vão desde Decifrando o código da Vinci até A fraude do código da Vinci, passando por $O$ caderno de viagens do código da Vinci.

4. Estou admitindo que livros como Decifrando o código da Vinci sejam interlocutores de $O$ código da Vinci.

5. Ainda no site de Dan Brown diz-se que o livro vendeu 50 milhões de cópias.
}

livros de apoio senão mercadorias que pegam carona no sucesso da primeira ao mesmo tempo em que ajudam a vender mais da mesma? Dan Brown não corre risco algum pela suposta denúncia que faz - até porque não faz denúncia alguma -, mas, quem sabe, poderia obter resultados econômicos negativos em ser parte de uma imensa estrutura de marketing que indistingue a claque contratada para aplaudir a "obra artística" e seus entusiastas espontâneos. Por exemplo, os citados representantes da Igreja Católica poderiam ter sucesso na recomendação ao boicote do livro/filme e haveria perda de exemplares e bilhetes vendidos. Porém, só a mobilização destes já seria capaz de gerar grande interesse pelo "segredo" do livro/filme. A novidade, porém, não está aí: os grupos conservadores que se rebelaram contra o rebolador Elvis Presley em sua primeira aparição televisiva também fizeram propaganda gratuita dele. A diferença fundamental reside no fato de que, como efeito do aparato usado para a venda das mercadorias, a comercialização de uma alegoria (no caso, a alegoria é a existência de sociedades secretas que guardam segredos terríveis) se faz na sua transformação em "coisa real".

Poder-se-ia então imaginar que a venda de livros/bilhetes de cinema contendo alegorias saborosas ao paladar de grande número de leitores teria a capacidade de transformar em "verdade" qualquer coisa? Não creio que tal resposta possa ser obtida pela simples reflexão conceitual, mas dou um exemplo: imaginemos um romance sobre o assassinato de John Lennon que defendesse a tese de que Paul McCartney fosse o seu real mandante, afinal, uma narrativa de um ciúme entre os dois teria tudo para ser verossímil. Seguir-se-ia uma avalanche de livros apócrifos - leitura de apoio - a discutir a fábula, reunir documentos contra e a favor dela, haveria debates em programas de TV com acusadores e defensores voluntários, teríamos milhares de leitores excitados por saberem de um (suposto) segredo e revoltados por terem sido (supostamente) enganados pela "versão oficial". Por fim, um fã de John resolve vingar a morte do ídolo e tenta matar Paul. Em torno disso, milhões de livros seriam vendidos e, caso o livro virasse filme, outros milhões de ingressos engordariam 
as contas dos grandes estúdios... ânimos teriam se exaltado, uma realidade teria sido criada e vivenciada pelas pessoas, enfim, uma estimulação extraordinária da energia e criatividade humanas cujo único interesse seria fazer girar a roda da acumulação capitalista.

\section{Alguns outros casos recentes}

Um outro relato nada desprezível é o do filósofo esloveno Slavoj Zizek narrando a experiência de ver Matrix ${ }^{6}$ no cinema (Zizek, 2003, p. 259). Primeiramente, achou curioso que uma rede de pessoas o tenha impelido a ver o filme dizendo-lhe que, entre outras coisas, este era revelador da filosofia pós-moderna e outros adjetivos do gênero. Além disso, ao chegar na sala de cinema, Zizek notou a excitação de um homem em torno dos 30 anos sentado ao seu lado que assistia ao filme como se fosse um adolescente abismado com uma revelação secreta. Meus Deus, então não existe realidade!, dizia o homem em voz alta durante o filme. Zizek considerou tal episódio muito mais curioso que o próprio filme (que obviamente não contém nenhuma revelação filosófica nem explícita nem subliminar). Creio que se deva notar ainda que o caso citado por Zizek não fora um caso isolado nem muito menos um fenômeno gratuito: observando o noticiário feito sobre o filme na época, destaca-se a valorização das cifras extraordinárias de gasto com a produção e de espectadores que o filme estava tendo ao redor do mundo. Ou seja, toda uma rede de informações dizia que ver aquele filme era fazer parte de um grande evento mundial. Portanto, estar extasiado diante dele não seria um acontecimento gratuito nem deslocado.

Um caso brasileiro seria a cobertura jornalística em tom polêmico do filme $A$ paixão de Cristo ${ }^{7}$ dirigido por $\mathrm{Mr}$. Mad Max. ${ }^{8} \mathrm{Na}$ época,

6. O filme que deu origem a duas continuações e foi tema de alguns documentários foi lançado em 1999 pelo estúdio estadunidense Warner Bros. Foi dirigido pelos irmãos Wachowski e protagonizado por Keanu Reeves.

7. O filme foi lançado em 2004 pela estadunidense 20th Century Fox/Icon Entertainment International. Foi dirigido por Mel Gibson e protagonizado por James Caviezel. Todas as informações sobre os filmes foram colhidas no site http://adorocinema.cidadeinternet.com.br/filmes.

8. Mad Max é o filme (seguido de duas continuações) que lançou o ator australiano Mel Gibson como big star do cinema australiano e estadunidense (logo, mundial). circulou um boato de que o filme teria sido prescrito (veja bem, prescrito e não proscrito) por clérigos de diferentes matizes cristãos como tarefa de formação teológica. Tal prescrição não deixa de ser curiosa, pois, ao fazê-la, os clérigos perdiam sua tradicional onipotência sobre o tema. No entanto, o fenômeno que mais me chamou atenção foi a notícia de que pessoas "passavam mal" durante o filme, havendo maior destaque para os próprios clérigos que deixavam as salas de cinema sob forte emoção, e tudo isso culminando na morte de um padre de algum país da Europa por ataque cardíaco momentos após deixar a sala de projeção. Com esse enfoque, a "grande imprensa" (que, se pensarmos bem, agia então como mídia de apoio ao filme) parecia querer insinuar que tais pessoas, justamente por serem dedicadas à religiosidade, acabavam mais afetadas pela verdade do filme.

\section{O grande lançamento cinematográfico}

Nos casos citados anteriormente, salta aos olhos o seguinte fenômeno: o evento noticiado pela mídia e que, por causa da cobertura, passa a ser um assunto generalizado não é nem poderia ser um debate sobre o conteúdo do filme, mas sim um tratamento espetacular dele que se faz passar por uma simples "cobertura jornalística". Como diz Debord, "a linguagem do espetáculo é constituída de sinais da produção reinante, que são ao mesmo tempo a finalidade última dessa produção" (Debord, 1997, p. 15). Os noticiários ${ }^{9}$ jornalísticos sobre ambos os filmes falam nos milhões de dólares gastos em efeitos especiais, nos milhões de espectadores pelo mundo, falam sobre inúmeros episódios acessórios do filme (a preparação dos atores, os cachês pagos, idiossincrasias das celebridades envolvidas) e noticiam supostas polêmicas despertadas pelo filme ao redor do mundo. ${ }^{10}$ Tudo isto, por si só, já vale não só a obrigatoriedade do indivíduo comum em participar do evento em questão (participação passiva que se resume a pagar o ticket), mas princi-

\footnotetext{
9. Refiro-me aqui tanto aos noticiários de forma geral como aos especializados em cinema.

10. "O espetáculo é o momento em que a mercadoria ocupou totalmente a vida social. Não apenas a relação com a mercadoria é visível, mas não se consegue ver nada além dela: o mundo que se vê é o seu mundo" (Debord, 1997, p. 30).
} 
palmente a intimação em admirar algo grandioso e conferir credibilidade ao objeto de admiração: se a coisa é revestida de tal aura espetacular, ela se torna imediatamente relevante, antes e independentemente de seu conteúdo. Em suma, a suposta cobertura, na verdade, dá sinais que indicam a necessidade de se assistir ao filme. "Quando o mundo real se transforma em simples imagens, as simples imagens tornam-se reais e motivações eficientes de um comportamento hipnótico" (Debord, 1997, p. 18).

Mas a cobertura jornalística não entra neste caminho à toa. Os produtores desse filmes criam material específico para alimentar tal apresentação (e posterior consumo) espetacular de seus filmes. Hoje em dia, um "grande filme" não é lançado sem o apoio de uma série de "autoelogios": toda uma gama de mercadorias acessórias, que vão desde o trailer oficial até o chamado making of do filme, revela que produto artístico e produto mercantil não podem ser diferenciados. Na verdade, são mercadorias que se adulam umas às outras e nos convidam, por um princípio mimético, a fazer o mesmo. "O espetáculo que inverte o real é efetivamente um produto. O caráter tautológico do espetáculo decorre do simples fato de seus meios e, ao mesmo tempo, seus fins" (Debord, 1997, p. 17).

Isso é especialmente importante no fenômeno Matrix: o adolescente excitado narrado por Zizek certamente foi alimentado por uma série de informações "plantadas" pelos próprios produtores do filme direta ou indiretamente (documentários, filmes explicativos e até leituras de apoio). A partir delas, disseminou-se a crença de que há algo por trás do filme, de que ele é detentor de camadas que são decifráveis mediante a inserção anterior do espectador no universo Matrix, a crença de que existe um mistério a ser desvendado e, que para ser desvendado, demanda o consumo desse material de apoio. Sem isso, o garoto teria de se contentar em assistir ao filme e produzir ele mesmo julgamentos sobre ele. A onda Matrix assim como as ondas Guerras nas estrelas ou Senhor dos anéis, e tantas outras que ainda virão, nada mais são do que típicos eventos espetaculares nos quais tanto o produto que se quer que seja consumido como a necessidade e a capacidade das pessoas em consumir tais mercadorias são produzidos por um mesmo grande aparato mercantil:

Ondas de entusiasmo por determinado produto, apoiado e lançado por todos os meios de comunicação propagam-se com grande rapidez. Um estilo de roupa surge de um filme, uma revista lança lugares de moda, que por sua vez lançam as mais variadas promoções... O homem reificado exibe a prova de sua intimidade com a mercadoria. Como nos arroubos dos que entram em transe ou os agraciados por milagres do velho fetichismo religioso, o fetichismo da mercadoria atinge momentos de excitação fervorosa. O único uso que ainda se expressa aqui é o uso fundamental da submissão. (Debord, 1997, p. 44)

A "cobertura jornalística" sobre esses megalançamentos nada mais faz que reverberar esse discurso, tirando-lhe a pecha de discurso promocional e conferindo-lhe um ar de relato verídico sobre uma realidade. É importante entendermos, a partir do trecho acima, que a participação das massas nesses eventos (as horas nas filas na pré-estréia do Guerra nas estrelas - Episódio 55) é meramente uma prática mimética, na verdade, é uma submissão delas a uma emoção e a uma mística préfabricada com o intuito de que se pague o bilhete do cinema.

\section{Um breve comentário paralelo (porém essencial)}

Ainda que não seja o tema deste ensaio, cedo à tentação de interpretar um dos efeitos espetaculares desses lançamentos cinematográficos: os clérigos que teriam se exaltado diante do realismo de A paixão de Cristo e sofrido de subidas de pressão, desmaios e coisa do tipo. Se for mesmo verdade que o filme causou aumentos de pressão arterial, pareceme provável que isso tenha ocorrido por um engano induzido pela mídia envolvida no lançamento do filme. Os clérigos que se sentiram mal ao ver o filme, talvez por idade ou mesmo pelo exercício do ofício, não haviam sido devi- 
damente "socializados" na linguagem que notabilizou o sr. Máquina mortífera ${ }^{11}$ como big star.

Quem, como eu, foi criança nos anos 80 e viu as inúmeras continuações cinematográficas estreladas por Charles Bronson, Silvester Stallone, Steven Segal e outros provavelmente sentiu um incômodo bem suportável na sala de cinema ao ver o filme. Isso porque fomos formados na cultura do cinema como "decalque mercantil de impulsos infantis" (Schneider, 1973, p. 311). Narrativas como Desejo de matar e Cobra não permitem qualquer nível de sublimação como antigos filmes românticos de Hollywood: mostra-se o indivíduo sendo vítima de violências para, no momento seguinte, levar o espectador ao delírio com o revide igualmente violento do personagem principal com o qual somos levados a nos identificar. Minha hipótese é de que, sem saber que o filme era "O Evangelho segundo Charles Bronson", ${ }^{2}$ clérigos afluíram para as salas de cinema que, há tempos, não lhes ofereciam nada muito específico. Chegando lá, se depararam com uma estética para a qual não estavam preparados. Para as novas gerações, acostumadas aos sombrios cenários da realidade virtual do PlayStation nos quais as crianças se divertem metralhando pessoas, a fotografia do filme não causou nenhum impacto extraordinário. No entanto, deveria ser mais do que pode agüentar alguém acostumado ao universo açucarado das telenovelas brasileiras.

Para o seu público como ator, o diretor ofereceu a mensagem possível: longas cenas de tortura mostrada com "realismo" maior que os noticiários televisivos mais sensacionalistas. Lembrem-se: antes de ser diretor desse filme, Mel Gibson podia ser visto em produções nas quais ele conta piadas antes e depois de balear pessoas em escala industrial (como no caso dos filmes da série Máquina mortífera). Para o público estreante em filmes que respingam sangue, uma difícil situação: pelo discurso espetacular em torno do filme, foram informados de que ele é algo a ser levado a sério; uma vez

11. Refiro-me a uma outra série de filme de grande sucesso mundial estrelado pelo ator Mel Gibson.

12. Cito o ator estadunidense como símbolo (talvez injusto pela sua longa trajetória cinematográfica) dos filmes truculentos nos quais a violência é festejada como estilo altivo de vida. diante da tela, depararam-se com algo insuportável, mas que, pela mensagem incutida na propaganda do filme, sentiam-se na obrigação de agüentar. É provável que alguns tenham mesmo se sentido mal. É como se uma pacata senhora fosse jogar Destruction Derby com seu neto e se sentisse na obrigação de levar a sério o que acontece na tela - pessoas se desmanchando em massas sanguinolentas após serem atropeladas por um carro pilotado por ela mesma.

Analisando brevemente o drama original dos Evangelhos, parece-me que ele seria enquadrado na categoria "filme-cabeça" para os espectadores do Gibson-ator. Nos Evangelhos, Cristo surge como um ser dividido que, vez por outra, retira-se solitariamente para montanhas e desertos inóspitos tentando decifrar sua dura condição: um ser que é, ao mesmo tempo, homem e Deus e que, como tal, é onisciente da extrema dificuldade em fazer com que os homens entendam sua mensagem (já que estes têm o livre-arbítrio para escolher o caminho mais fácil, o caminho do mal). O mesmo Cristo, além disso, tem uma dura missão pela frente: sendo onipotente (como Deus), só pode exaltar sua mensagem de amor pondo seu frágil corpo humano à disposição da maldade desses homens que ele pretende salvar. Portanto, não é sem base que a filmografia sobre esse drama sempre trouxe um Jesus enigmático, distante e, às vezes mesmo, perturbado. O filme em questão não fugiu a essa regra, mas esta não é a sua tônica: a história que todos sabemos o começo, meio e fim só pôde ser um grande evento midiático porque seu diretor a trouxe para a era da violência como estética.

Se a doutrina cristã nos apresenta o drama de seguirmos uma ordem espiritual (que manda sermos bons) em pleno mundo material (que manda sermos maus), provocando uma angústia, o choque desse filme paralisa qualquer reflexão justamente porque, ao sair do cinema, o público só tem duas alternativas: ou exclama a favor da técnica cinematográfica em simular sangue e feridas ou se dedica a esquecer tais imagens bizarras. Não é angústia que sentimos, mas simplesmente vontade de esquecer. Como substituto dos profundos dramas psicológicos insolúveis da trama cristã original - que provavelmente não interessariam ao policial de 
Máquina mortífera que está sempre comendo cachorros-quentes -, o filme dirigido por Mel Gibson mostra insistentemente um corpo banhado em sangue como bandeira de uma mensagem inexistente. O filme é, na verdade, um sintoma. É um sintoma de que qualquer história cabe no rolo compressor da indústria do entretenimento: não queremos que você pense, apenas oferecemos alguma euforia, distraiase com ela, volte para casa e, quando precisar de mais doses de euforia, estaremos aqui, com novas sensações postiças pelas quais você pagará a módica quantia do ingresso no cinema!

\section{É uma falta de absurdo!}

Gostaria de encerrar fazendo uma alusão a duas grandes peças do chamado Teatro do Absurdo: Esperando Godot, de Samuel Beckett, e As cadeiras, de Ionesco. Em ambas, temos o horror das pessoas comuns com a sensação de alienação, com a sensação de que não entendem o que se passa na sociedade e de que são incapazes de se inserir nessa ordem inóspita. Ainda nas duas peças, tal horror só pode ser "administrado" por causa de uma crença desesperada num acontecimento iminente e extraordinário que acabaria com essa sensação de absurdo e impotência, recolocando tudo em seu lugar (as coisas, as pessoas em geral e, por consequiência, os personagens). É certo que, nas duas peças, esse momento jamais chega. Seria uma derrota total do indivíduo? Nem tanto, isso porque, mesmo sem saber onde procurar esse sentido, eles seguem buscando-o entre suas "entranhas" formadas de idéias supostamente originais, suas utopias pessoais, análises caóticas e debates enviesados. Em suma, esses personagens ainda são capazes de transformar o incognoscível em angústia existencial, ou seja, o desespero faz surgir um espaço de elaboração subjetiva, de autocultivo como última esperança em derrotar o caos.

Pois muito bem: parece-me que a indústria total que gera os eventos cinematográficos que estudamos no artigo (e aqui me refiro especialmente ao caso Matrix) realiza, na prática, o maior absurdo possível para Ionesco e Beckett. Quando as pessoas buscam no consumo espe- tacular de Matrix a revelação do suposto segredo da "sociedade digital", é a própria "sociedade digital" (que, seja lá o que ela for, é quem responde pelas condições que permitem a audiência espetacular do filme) quem se coloca como reveladora de si. Em outras palavras, diferentemente dos personagens do Teatro do Absurdo, o indivíduo que revira os escombros de material publicitário (em vez de seus próprios escombros), em busca da decifração do "segredo", atinge o auge do processo de alienação: ele busca na própria relação alienante ${ }^{13}$ uma redenção. Além disso, diferente do final trágico das peças nas quais a resposta sobre o sentido das coisas nunca chega (situação que indica a necessidade de que se continue a procura), a assistência espetacular de Matrix permite ao espectador participar de sua mística sem no entanto viver a angústia de estar diante de uma narrativa sobre a qual não se sabe o fim ou a "moral da história". O filme no qual foram gastos milhões com efeitos especiais produzidos em computadores sofisticados e que se valeu de inúmeras mídias eletrônicas para se promover é justamente aquele que nos revela, em tom supostamente radical, o segredo da sociedade digital. Parece estranho, não?

\begin{abstract}
This article takes the entertainment's industry as a strategic focus to understand the "spetacle society" theory. For this, we pay an especial atention on the big cinematographic's events to launch films like The DaVinci Code, The passion of Christ and Matrix.
\end{abstract}

Key-words: cinema; spetacle's society; capitalism.

\section{Referências}

DEBORD, G. A sociedade do espetáculo. Rio de Janeiro: Ed. Contraponto, 1997.

SCHNEIDER, M. Neurose e classes sociais: uma síntese freudiano-marxista. Rio de Janeiro: Zahar Editores, 1973

ZIZEK, S. Matrix ou os dois lados da perversão. In: IRWIN, William (Org.). Matrix: bem-vindo ao deserto do real. São Paulo: Ed. Madras, 2003.

13. No sentido de que o cinema, como espetáculo, cria símbolos com os quais o espectador é levado a identificar suas necessidades e desejos. 